\title{
Tools, Not Rules: Are We Teaching the Wrong Principles of Economics in the Introductory Course?
}

\author{
David Colander \\ Middlebury College, Middlebury, Vermont 05753, USA.
}

Eastern Economic Journal (2016) 42, 163-168. doi:10.1057/eej.2015.57

The teaching of introductory economics is often organized around a set of principles. Those principles provide a useful structure around which additional discussion can be organized. Having these principles is pedagogically efficient; they make grading easier, and help students remember the material.

Critics of economics often object to these economic principles, arguing that we are teaching the wrong principles. I disagree; the principles we teach are fine, as long as they are presented with the appropriate nuance, by which I mean that we emphasize that the principles are tools, not rules. Used appropriately, these principles can be highly useful. Used inappropriately, these principles can undermine student's understanding of economics.

Many professors add the needed nuance in their lectures, and textbooks generally add it in their in-depth discussions. Unfortunately, students often have a hard time integrating the inclass presentation of nuance into their understanding of the principles. They focus on memorizing the principles because that's what they believe that the exam will focus on. The problem is getting worse. More and more, the teaching of economics is being built into online learning systems structured around the principles found in the texts. The online learning systems are structured so that they highlight only the principles; they purposely blur out the discussion where the nuance generally exists so that students aren't distracted by the discussion. That, in my view, is a problem. It means that unless the nuance is directly embedded in the highlighted principle, the nuance is lost.

\section{TEN NUANCED PRINCIPLES OF ECONOMICS}

Currently, the principles of economics are often presented in a way that does not embed the nuance in the principle so that when the students learn the principle, they also learn the nuance. It doesn't have to be that way. In this section I list 10 standard principles of economics and then suggest a nuanced way to present them. I also provide a brief discussion of how the nuanced principle differs from the standard principle and why the nuanced presentation is preferable. In the table at the end of the discussion, I contrast my nuanced principles with the principles as they are often presented in the principles' texts. 


\section{(1) The trade-off principle}

The trade-off principle is central to economics. The nuance that needs to be incorporated into this principle is that the process of making trade-offs is much more complicated than can be presented in the beginning course in economics. It is because it is more complicated that economists' cutting edge research in behavioral economics is working on expanding our understanding of real world decision making. Presenting choice analysis as a clear-cut and simple principle, as principles textbooks often do, is itself just a trade-off made by textbook writers. Students will have a much better sense of how to apply economics if they are told right from the get-go that the models they learn in economics miss many dimensions of decisions. A nuanced presentation of the trade-off principle would include a caveat that reminds students that once in a while, a win-win situation is possible. So my suggested nuanced trade-off principle is:

(1) There is no such thing as a free lunch, but once in a while one can snitch a sandwich.

\section{(2) The opportunity cost principle}

The opportunity cost principle reinforces the "no free lunch" principle, and also reminds students to consider implicit, as well as obvious, costs (and benefits). But implicit costs and implicit benefits have many dimensions, and an appropriate use of economist's cost-benefit framework needs to remind students that before they apply cost-benefit analysis, they need to take these many dimensions into account. The nuance that needs to be built into the principle is that the cost-benefit economic framework is a tool, not a rule.

(2) Opportunity cost focuses economist's cost-benefit framework on non-obvious as well as obvious tradeoffs, and serves as a useful heuristic for decision making.

\section{(3) The rationality cost/benefit principle}

The rationality principle is fundamental to the teaching of economics. We all tell students that a rational decision maker takes action if the relevant benefits of taking the action exceed the relevant costs. What we don't tell students is that defining rationality in a non-tautological way is really difficult, and the models we teach them lose many dimensions of people's decision-making process. A key example occurs when the rationality principle is embedded in marginal decision making. The "benefits exceed costs" decision rule applies whether or not they are marginal costs or non-marginal costs. The "marginal" nature of the costs is relevant for decisions that involve marginal decisions, and that have the correct second-order conditions. Many real world decisions are not marginal decisions, in which case the standard marginal formulas don't apply directly. Since, in reality, we have no way of defining what is rational, or what costs and benefits to a person are, the "rational choice" principle is best presented as a tautological framework that is extremely useful if treated as what it is: a useful heuristic - a tool, not a rule.

(3) Framing a question in a cost-benefit lens is useful as long as the lens is seen as a tool, not a rule; the economy is a complex system requiring multiple lenses to capture its many dimensions. Good economists always qualify their models with "other things equal." 


\section{(4) The incentive principle}

The incentive principle is also best seen as a tool not a rule. It is trivial to say that people respond to incentives. (Yoram Bauman (https://www.youtube.com/watch?v= LPUEgEdCTp8) wonderfully describes it as a tautological tautology.) The relevance of this tautology is embedded with the nuance: A nuanced presentation of the incentive principle would emphasize that price incentives - the incentives economic models focus on - are just one of a set of incentives; there are many other types of incentives as well. Moreover, the actual incentives that people respond to are embedded in institutions that the simple principles' models don't capture. So extreme care should be used when extending this principle to policy questions. A more nuanced incentive principle is:

(4) Most people are driven by enlightened self-interest in achieving their personal and social goals. As the costs and benefits of achieving these goals change, behavior changes.

\section{(5) The "trade is good" principle}

Trade and specialization are central to economics, and the ability to trade is what Adam Smith said separated man from animals. But trade is best understood as part of a broader system of social cooperation; trades that occur in markets are only one form of cooperation among people. A nuanced "trade is good" principle would emphasize that cooperation can make society better off, and that trade in markets is an important way in which cooperation leads to coordination. It would also point out that cooperation inevitably requires difficult trade-offs. The nature of that coordination should be seen as having many dimensions, of which market trades are but one.

(5) Trade is a form of cooperation and cooperation can make everyone better off. Complicated trades require complicated institutional and social foundations.

\section{(6) The "markets are good" principle}

This principle can lead students to miss the interconnection between markets and the government. The nuance that is missing is that legal and cultural support of the property rights upon which markets are built are necessary for complex markets to operate. Thus the government and markets are intricately entwined; they should not be seen as opposites. Effective markets exist where the difficult decisions about distribution of property rights have been answered by the society and government protects and supports the market. The efficient use of markets requires a deep level of planning by the government that involves creating an ecostructure conducive to markets and other bottom-up solutions to problems.

(6) Markets offer a useful way for societies to coordinate actions. The efficient use of markets evolves over time. One aspect of government policy involves creating an ecostructure conducive to markets and other bottom-up solutions to problems.

\section{(7) The externality principle}

The standard presentation of the externality principle often makes it sound as if markets exist independently, and are not grounded within a cultural and political setting that is itself created by the government. The government and market are intricately entwined. Public policy involves much more than just correcting market outcomes. It involves influencing 
the evolution of markets so that top-down interventions into market outcomes are not necessary. There are arguments for and against the government intervention that extend beyond the model. Not only are there market failures and government failures, there are also failures of market outcomes and failures of government outcomes.

(7) Government and the market are intricately entwined. Public policy involves much more than just correcting market outcomes. It can also involve influencing the evolution of institutions so that top-down interventions into market outcomes are less necessary.

\section{(8) The "real" principle}

The "real" principle is designed to get students to look behind the veil of money and to think about real goods and services. Often the "real" principle is presented in a way that it is tautologically true and thus says nothing but that only when you produce more do you have more. The potential lack of nuance occurs when the focus of the "real" discussion is on goods and services only, as if material welfare were all that mattered. Economics is part of a broader set of social issues, of which the goods and services measured by GDP and productivity are only one aspect of society's welfare. GDP, which is often used as a focus of macroeconomic policy, is not a good measure of these broader aspects of welfare. What is "real" is decided by people, not by accountants.

(8) A country's well-being depends on more that the material welfare that economics focuses on. The goods and services measured by GDP and productivity measures are only one aspect of social welfare. GDP misses many of these broader aspects.

\section{(9) The "money illusion" principle}

Often, the money illusion principle is presented as one in which increases in money cause increases in prices. Presented this way, the money illusion principle is not only not nuanced, it is seriously misleading. There are two serious problems with it. First, it does not describe recent experience. In recent years, the government has created enormous amounts of money, and prices have not risen. The second is that it directs students to see only the demand side, and leaves out the supply side. My alternative tautological statement that captures the problem of inflation is that "Prices rise with price setters have incentives to raise their prices." This provides a more nuanced principle for students that directs them to think about both supply and demand forces in the aggregate economy.

(9) Ultimately, the amount of real goods in the economy, not the amount of money in the economy, limits the amount that society can consume. Prices rise when sellers have incentives to raise their prices and demanders are willing to pay those higher prices.

\section{(10) The macroeconomic policy principle}

This principle is often presented as meaning that there is always an inflation/ unemployment trade-off. Presented in that way it is a lousy general principle. Inflation and unemployment are intricately connected, but not in any simple relationship as this principle suggests. The macro economy is best seen as a complex system in which supply and demand forces are intertwined, and many different outcomes are possible. Economists don't have good theories of the macro economy, and students should be told that. We have some general heuristic models that help guide policy, but they are highly imperfect. Often policies that are helpful in the short run are not helpful in the long run and vice versa. 
A more nuanced principle would emphasize that in the aggregate supply and demand forces are intertwined. So I would replace it with:

(10) Aggregate supply and demand forces are intertwined; many possible outcomes are possible. Economists don't have good theories of the macro economy.

\section{CONCLUSION}

The nuanced principles I presented are principles that good economists use when they are applying economics. That's why I defend economics against its critics. Unfortunately, when the nuance needed to apply those principles is separated from the principles themselves, the full understanding of those principles can be lost on students. All too often the nuance has been lost in our teaching of principles. Since the principles of economics course is the face of economics to much of the lay public, they misunderstand economics. That's sad.

It wasn't always the case. When one reads John Stuart Mill's or Alfred Marshall's Principles of Economics, the nuance of economic reasoning clearly comes through. They present economic principles not as doctrines providing truth, but as a method of thinking. Their economic principles were presented as tools not rules. It is time for us to return to our roots, and bring back the nuance into our presentation of economic principles.

Comparison of nuanced and standard principles of economics ${ }^{\mathrm{a}}$

Nuanced principles of economics Standard principles of economics

- The trade-off principle: There is no such thing as a free lunch, but once in a while one can snitch a sandwich

- The opportunity cost principle: Opportunity cost focuses economist's cost-benefit framework on non-obvious as well as obvious trade-offs, and serves as a useful heuristic for decision making

- The rationality cost/benefit principle: Framing a question in a cost-benefit lens is useful as long as the lens is seen as a tool, not a rule; the economy is a complex system requiring multiple lenses to capture its many dimensions. Good economists always qualify their models with "other things equal"

- The incentive principle: Most people are driven by enlightened self-interest in achieving their personal and social goals. As the costs and benefits of achieving these goals change, behavior changes.
- People face trade-offs: To get one thing, you have to give up something else. Making decisions requires trading off one goal against another

- The cost of something is what you give up to get it: Decision makers have to consider both the obvious and implicit costs of their actions

- Rational people think at the margin: A rational decision maker takes action if and only if the marginal benefit of the action exceeds the marginal cost

- People respond to incentives: Behavior changes when costs or benefits change 
- The trade is good principle: Trade is a form of cooperation and cooperation can make everyone better off. Complicated trades require complicated institutional and social foundations

- The markets are good principle: Markets offer a useful way for societies to coordinate actions. The efficient use of markets evolves over time. One aspect of the government policy involves creating an ecostructure conducive to markets and other bottom-up solutions to problems

- The externality principle: The Government and market are intricately entwined. Public policy involves much more than just correcting market outcomes. It can also involve influencing the evolution of institutions so that top-down interventions into market outcomes are less necessary

- The "real" principle: A country's wellbeing depends on more than the material welfare that economics focuses on. The goods and services measured by GDP and productivity measures are only one aspect of social welfare. GDP misses many of these broader aspects

- The money illusion principle: Ultimately, the amount of real goods in the economy, not the amount of money in the economy, limits the amount that society can consume. Prices rise when sellers have incentives to raise their prices and demanders are willing to pay those higher prices

- The macroeconomic policy principle: Aggregate supply and demand forces are intertwined; many possible outcomes are possible. Economists don't have good theories of the macro economy
- Trade can make everyone better off: Trade allows each person to specialize in the activities he or she does best. By trading with others, people can buy a greater variety of goods or services

- Markets are usually a good way to organize economic activity: Households and firms that interact in market economies act as if they are guided by an "invisible hand" that leads the market to allocate resources efficiently. The opposite of this is economic activity that is organized by a central planner within the government

- Governments can sometimes improve market outcomes: When a market fails to allocate resources efficiently, the government can change the outcome through public policy. Examples are regulations against monopolies and pollution

- A country's standard of living depends on its ability to produce goods and services: Countries whose workers produce a large quantity of goods and services per unit of time enjoy a high standard of living. Similarly, as a nation's productivity grows, so does its average income

\section{- Prices rise when the government prints} too much money: When a government creates large quantities of the nation's money, the value of the money falls. As a result, prices increase, requiring more of the same money to buy goods and services

- Society faces a short-run trade-off between inflation and unemployment: Reducing inflation often causes a temporary rise in unemployment. This trade-off is crucial for understanding the short-run effects of changes in taxes, government spending, and monetary policy

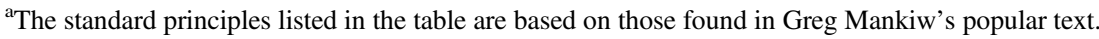

